\title{
Perceptions Of Lakota Native American Students Taking Online Business Course At Oglala Lakota College (OLC)
}

Ahmed Al-Asfour, Oglala Lakota College, USA Carol Bryant, University of Wyoming, USA

\begin{abstract}
This research examined the perceptions of Lakota Native American students taking a Business online course at the Oglala Lakota College on the Pine Ridge Reservation. The study was conducted in the fall of 2010 and spring of 2011. The themes found in this study were flexibility, transportation, communication, and technical support. Furthermore, the study found some of the advantages for students taking online courses as well as some obstacles encountered by students on the reservation.
\end{abstract}

Keywords: Business Online courses; Lakota Native American students; Oglala Lakota College; Pine Ridge Reservation

\section{INTRODUCTION}

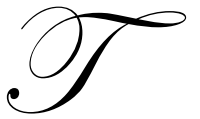

he advent of the Internet has significantly contributed to the boom in educational technology and rapid growth of distance education, and this includes online courses. Although online courses have been very prevalent in many educational institutions, very little research that has been done on the Lakota Native American colleges, especially at Oglala Lakota College (OLC). Based on the investigation of peer reviewed literature and to the knowledge of the authors on this topic, there is not a single research study that has been done about this topic at OLC or any other Lakota tribal college, even though online education has been researched extensively.

This research attempted to examine the perceptions of Lakota Native American students who were taking the Principles of Marketing online course through the OLC Business department during the fall 2010 semester. The study has helped the Business Department faculty to gain an understanding of the barriers and challenges students experience when taking online courses. More importantly, it can be helpful to OLC to understand the perceptions of its students who take online courses. The information herein may also be beneficial to other tribal colleges to examine their online practices.

\section{The Online Approach}

Online education is a method of instruction that allows students to use the Internet as a means of providing education regardless of where they are located. The use of the Internet in course delivery was slow to take hold in the mid 1990s, but in a relatively short time, the medium of online delivery has, in large part, replaced the method of face-to-face (f2f)). Kearsly (2000) reported the following themes that shape online education: "collaboration, connectivity, student-centeredness, unboundedness, community, exploration, shared knowledge, multisensory experience, and authenticity" (p.4).

Currently, the predominant method of distance-based course delivery is by online means. Best practices of this kind of education have been studied by Beaudoin( 2002) and other researchers. 
The accessibility and affordability for the technology required by this method enables students to take advantage of online education. Online learning is growing, with enrollment that is expanding, as part of an estimated $\$ 2$ billion business industry (Thomas, 2001). These numbers have increased tremendously with the number of online universities. Online courses and e-learning have become omnipresent in both distance and blended modes for formal education and informal learning contexts. The majority of university students today in the United States have grown up with the Internet, email, mobile phone and most of the latest technology. This required university professors to adapt as well. While there are some classes that are taught solely online, there are others that use f2f and blended learning, which are called hybrid courses. Blended learning is expanding, and debate of the quality of education, particularly regarding student learning and satisfaction continues (Noble, 2003).

The purpose of this qualitative study is to gain a better understanding how students view their online courses. The major question this research is, what are the perceptions of Lakota Native American students taking online courses?

\section{LITERATURE REVIEW}

Although the literature regarding online education is expanding, studies that are related to Lakota specifically and Native Americans in general are very limited, especially when it comes to students' perceptions of online courses. "The key concern is understanding the phenomenon of interest from the participants' perspectives, not the researcher's. This is sometimes referred to as the emic, or insider's perspective, versus the etic, or outsider's view" (Merriam, 2009, p. 14). Despite the research done on this particular topic, a limited number of studies have been conducted on the perceptions of students towards online courses (Dobbs, Waid, \& Del Carmen, 2009). Because of this, some of the literature reviews mentioned in this article are more than ten years old. The following literature reviews will address history of OLC, distance education and tribal colleges and distance education and native students.

\section{History of OLC}

The Pine Ridge Reservation, or as it is called by many Lakota - Oglala Oyank - is known as Pine Ridge Agency. The reservation is located in the southwest corner of South Dakota and consists of 3,468.86 sq mi. The reservation is larger than Delaware and Rohode Island combined or the state of Connecticut. In addition, the Pine Ridge Reservation is one of the largest reservations in the United States, and it is the home of OLC.

Tribal colleges are rooted in the desire of tribes to have greater control in the education of their members, which is referred to as self-determination, and to have access to postsecondary education on the reservations. OLC is no exception to the mission of most of the tribal colleges. According to OLC President's (Shortbull) message posted on the OLC website:

From its inception in 1971, our college's mission has been to provide the educational credentials to our students so that they could compete for employment opportunities on the Pine Ridge Indian Reservation. As a result of having a college on the reservation; Lakota people are now employed in teaching, nursing, human services, business, computer, and vocational educational positions on the Pine Ridge reservation. (Shortbull, http://www.olc.edu/about/)

The initial goal of OLC was to become a community college. However, the college now offers vocational degrees, associates, bachelors', and master degrees. The college is decentralized, meaning it has twelve college centers. Recently (2010), it added a virtual campus, which makes it the first and only Native American Tribal College that has a virtual campus. The virtual campus is designed for offering hybrid and online courses. OLC has been offering online courses as part of distance education for several years. The college does not offer online degrees, but rather it offers courses. It has also been using a program called PictureTel to reach districts within the Pine Ridge Reservation, Rapid City College Center and Cheyenne River Reservation. Even with some of the challenges OLC encounters, it is one of the leading Native American colleges in changing the face of American Indian education by providing rigorous academics alongside Lakota studies and language courses. For instance, students take courses such as Principles of Marketing and Accounting together with Lakota language and cultural courses. This not only prepares them for the future, but it also equips them to be who they are as Lakota people. 


\section{Distance Education and Tribal Colleges}

Tribal colleges use distance learning in order to provide education for tribal members while also reflecting and sustaining tribal cultures (Ambler, 1994). According to the same source, "tribal college administrators see telecommunications courses as an extension of their reason for being -- building academic achievement upon a strong cultural foundation. Ultimately, the envision[ing] of creation of a unique university without walls where the resources of all institutions are joined together electronically" (p.11). According to the Native American College fund, key facts about Native colleges are as follows:

- $\quad$ There are more than 30 tribal colleges that serve more than 30,000 students who represent more than 250 tribes from across the U.S., Mexico, and Canada.

- Tribal colleges are fully accredited institutions with the same academic standards as all other colleges and universities.

- Most tribal colleges operate on Indian reservations - providing access to higher education for people who otherwise would not be able to advance beyond a high school diploma.

- In addition to increasing academic achievement for students, tribal colleges promote students' self-esteem and cultural identity.

- Most tribal colleges receive no Indian casino revenue (Native American College Fund) http://www.collegefund.org/content/tribal_colleges.

According to Duncan and Young ( 2009) " Rapidly developing information and computer technologies capabilities that form the infrastructure for distance education fuel an expanding niche for distance education" (p.28). As tribal colleges move forward with online education, infrastructure of online courses will need to be improved throughout the reservations in order to accommodate this kind of education.

\section{Distance Education and Native Students}

With a high unemployment rate throughout Lakota country, especially at the Pine Ridge Reservation, many Lakota students worry about how to provide for their families prior to and while seeking education. This phenomenon in Native country is confirmed by Sanchez, Stuckey and Morris (1998):

The plethora of problems American Indian students face as a result of individual financial stress are exacerbated by family commitments. American Indian students often must first meet these obligations, then worry about their own situations. These tensions impose further burdens on students who may often lack adequate academic preparation for higher education (p.3).

Gavin (1997) reported "These disadvantages often lead to, and are deepened by, low faculty expectations, social and cultural isolation on mainstream campuses, and lack of support at home for the educational endeavor" (p. 13).

Many of OLC students encounter barriers in their education, one of which is having transportation to the college centers. Thus, distance learning offers potential advantages for these students and for the communities where they reside. According to Sanchez, Stuckey and Morris (1998), "Under the right conditions, these barriers can be at least partially reduced through the technologies of distance learning" (p.3). For example, evidence from Canada suggests that the links between sustainable economic development and distance education are clear (Wall \& Owen, 1992). The availability of distance education to the Lakota students has provided education to many rural areas as well as nontraditional students who cannot commit to being full-time students due to employment, family commitments and such.

Some of the reasons that lead Native American Colleges to distance education are geographical isolation of districts, physical disability, and poverty. Cross (1981) mentioned that institutional barriers can be one of five, one of which is "problems with location or transportation" (p.104).The technologies associated with distance education are, in one form or another, so widely available that everyone is potentially included. One conceivable, positive outcome of such inclusion is the possibility that this technology can serve to preserve, maintain, and 
revitalize traditional languages and cultures. While the dominant culture exerts tremendous pressure for assimilation to the general culture of the United States (Sanchez, 1997), this kind of pressure is often directed due to educational systems (Sanchez, Stuckey, \& Morris, 1998). While the coursers should be designed to accommodate cultural aspects, Duncan and Young (2009) mentioned that "The course must be structured to balance the goal of learner centeredness and leaner responsibility" (p.27).

\section{METHODOLOGY}

In this study, qualitative methods were used to examine the perceptions of Lakota Native American students taking the Principles of Marketing online course. The researcher received IRB approval from OLC to conduct this research followed by permission from the Principle of Marketing instructor. Further IRBs were requested for approval from Oglala Sioux Tribe and the University of Wyoming as this research was initially a part of a fulfillment of a class requirement. An email was sent to all students who were taking the course to solicit them to participate in this study. In order for students to be eligible for this study, students had to meet two main criteria: (a) a Lakota student taking the online Principles of Marketing course in fall 2010 (b) 18 years of age and over.

\section{RESEARCH QUESTIONS}

To accomplish the purpose of this study, the following questions were developed to reveal the perceptions of the Lakota Native American students.

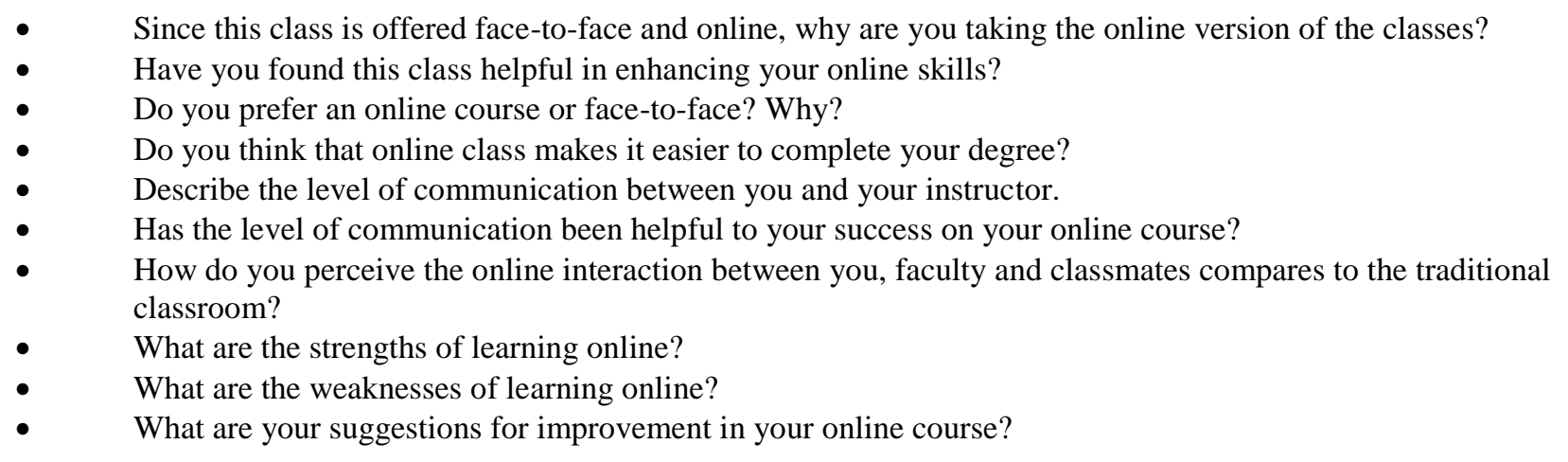

A semi- structured interview was conducted in this study. Some additional probing questions were asked to clarify statements during the interviews.

\section{Participants and Demographics}

The study was conducted in the fall 2010 and spring 2011 semester at OLC. Participants were mostly junior and senior students. The initial numbers of registered students during the semester was twenty five. By the time this research was conducted and an email was sent the students, there were twenty. Given the nature of this study, four students initially participated in this study after two requests were sent in fall 2010. Another student later decided to participate in the beginning of spring 2011 semester, which makes it five students out of a total of twenty students in the class. Students in this class were from different districts on the Pine Ridge Reservation, Cheyenne River Reservation, in Rapid City, SD, and perhaps other cities.

\section{Data Collection and Analysis}

Data collection of this study was garnered through a semi-structured interview with 10 open-ended questions. Some probing questions followed to better understand students' perceptions and to clarify statements from participants. Interviews took place with each participant individually in various college centers on the Pine Ridge Reservation and He Sapa (The Black Hills) College Center, which is located in Rapid City, SD. 
The data was coded based on students' answers and the themes that emerged from the coding were flexibility, transportation, communication and technical support.

\section{Limitations}

As with most qualitative research, it is very difficult to generalize this study to all OLC students. In this study, there are two shortcomings. First, the respondents' rate was 5 out of a total of 20 students, and there is no way of knowing whether the respondents' views represent the majority OLC online Business students. Second, all of the participants who have participated in this study were females. In fall 2010, there were 1255 (68\%) female students and $575(32 \%)$ male students attending OLC, according to the office of database administrator. Hence, male perceptions were not included.

\section{FINDINGS}

Participants were asked to describe their perceptions of taking an online course. The participants expressed their answers by explaining the positives and negatives throughout the process of taking the course. The themes that emerged in this study are discussed in the following paragraphs.

\section{Flexibility}

The flexibility of online education has been generally known to be one of the advantages in this kind of education delivery. All of students who participated in this study stated that by taking this course online, it offered them the opportunity to work full time and tend to their children. Some of students' answers were "I needed to go school full time as well as have a part time job, and by taking this class online, I was able to have an extra day to go to work instead of sitting in class." "I am a full time employee at OLC and student. It's nice to have a class in my living room, kitchen, library...you get the point." "If I become I sick can still be counted present." This participant was referring to attending class online even when she became sick. "Work full time and I would not be able to take this course otherwise." "It's a great opportunity to learn at home."

Another positive experience for students is self-paced learning. As two students noted "It's been a wonderful experience because I learn at my own pace without other people talking all at once." "I can work at my own pace." The participants had complete control of when and where to study. All they needed was a computer and the Internet to connect to class. One student mentioned that "I like how I can manage my time and work on the virtual campus. It's fun." "My class revolves around my time." In a traditional classroom, classes revolve around the instructor's time. Online education lets students schedule their classes based on their own needs. In addition, students felt that there was no pressure to answer teacher-generated questions right away. "In a 3 hour course, many students daydream, think about issues outside of their class and you know the rest of the story." In an online course students could reflect and contemplate their answers before posting anything on the course.

While there are many benefits to the flexibility of online education, there is one main disadvantage, and that is procrastination. Participants viewed that lack of self-regulation as a potential weakness in this educational setting. "My own personal time management is the weakness. I'm not really disciplined on managing my time and avoiding distractions." "A weakness of learning online is that you think you have a lot of time to get your work done, you keep pushing it back and pushing it back until you are way behind." The participants' answers show both advantages and disadvantages. When comparing participants' answers, the flexibility of online education seems to outweigh traditional education.

\section{Transportation}

Since the majority of the participants live on the Pine Ridge Reservation, they felt that transportation in general was an issue. OLC requires 6 students in a class in order for it to be taught in a college center. Some of the college centers do not have enough students to offer the Principles of Marketing course, thus students would need to drive to a larger college center to take this course. The problem with this is that some of OLC students do not have cars; therefore, this might present a challenge for them to take the course. "Public transportation is not reliable." "Online courses save driving time." By taking this course online, students would not need transportation. 
In addition to transportation on the reservation, weather conditions could be an issue to students. "One of the strengths in taking online courses is that students do not miss any classes due to weather conditions, you know we live in South Dakota." Adverse weather conditions occur a few times during the year, especially in the spring semester in which the entire area receives several blizzards that makes it impossible for students to attend classes at any of the college centers. One student puts it this way, "Taking this course online pretty much offers the answer to the weather problems we face." "Snow on roads does not get plowed right away."

\section{Communication}

The overall communication with instructor and participants was viewed as a positive experience. The instructor of the class answered e-mails and phone calls in a timely manner. "The virtual campus allows me to email the instructor and other classmates. The communication between all of us is really good." "I think that the level of communication between me and my instructor is very high." One participant mentioned that the level of communication is as equal as to $\mathrm{f} 2 \mathrm{f}$ classes. "I say this because there are times when the instructor is overwhelmed with other students and he/she cannot get to your questions(s)." "The online class provides a window where the instructor can answer your questions in a more detailed form of answer and plus he/she sent their phone number and the students can call if we really need to." In f2f, participants' felt that this level of communication does not take place.

The ease of connection to the Internet was also viewed as a positive experience due to the availability of the Internet at their college centers and homes. "I like the online course because I have access to the Internet and this enables me to do research as well as work on my assignments at the same time from home." "I have Internet access right at the touch of my fingertips."

Even though participants generally found communication to be positive, there was one weakness of communication, which is beyond the instructor and students' control: power surge do not happen often, but it was a potential risk which could prevent submitting assignments on time. "One weakness that I have encountered while taking courses online is when there is a power surge; I do not have connection to the class." The majority of participants did not express this concern; however, it is a potential risk, even if it is minor.

\section{Technical Support}

Some of the participants mentioned that technical support might not be available to them every day to resolve any issues that they might have. So, students sent their instructor e-mails to ask questions such as the process of accessing the course. One participant noted "Sometimes I need help and all I have to do is send my instructor an e-mail." This participant continued "I always get a reply from my instructor within a short time after it has been sent." Emailing the instructor of the class and receiving an answer could take some time, depending on the instructor's availability. A second participant responded by giving advice, "Maybe we should get a technical support help desk."

\section{CONCLUSIONS}

The purpose of this research study was to gain an understanding of the perceptions of Lakota student enrolled at OLC taking a business online course, the Principles of Marketing. The Semi-structured interviews were conducted to garner data of students' perceptions.

Flexibility of online learning was viewed as overwhelmingly positive by the participants. This was supported by (Yang \& Cornelius, 2004). Another study by Petrides (2002) mentioned that students appreciate the flexibility of online education. The flexibility of self-paced learning acknowledged a positive experience by the participants, but it also was negative as it undermines students' self-motivation. As one participant noted, "this can be a double-edged sword."

Participants in this study expressed that transportation and weather conditions during winter played a role in deciding to attend a college center in other districts or take a course online. The reservation has bus service; 
however, sometimes during the semester, students might not be able to use it as it conflicts with their times and weather could play a role in slowing down the service.

Another positive point in this study is communication. Participants mentioned that communication between them and their instructor had been "great." The participants received answers for their questions in a timely manner. Discussion boards in the class helped students to further their understanding of assignments and exams. One participant mentioned that "developing a chat session which requires students to $\log$ in at a certain time during the week will help to communicate with other students". As reported by Cakmak, Karatas, \& Ocak (2009), students prefer to interact with their classmates and instructor on a class chat online session. The final theme from this study was participants' concern of technical support. They expressed the idea of having a help desk. They want someone at the college to call to resolve any potential problem without sending irrelevant e-mails to their instructor.

Distance education, which includes hybrid and online courses, should continue to be a part of the Native American educational system as it offers an opportunity to nontraditional students to obtain higher education in various degrees. Many of the tribal colleges have been shifting the paradigm of teaching from $\mathrm{f} 2 \mathrm{f}$ to offering distance education courses for several years, and the trend continues to grow.

\section{FUTURE RESEARCH}

Future studies should attempt to research the entire business online courses at OLC or, on a larger scale, of all online courses being offered at the college. Qualitative studies such as this should continue to explore students' and instructors' perceptions, satisfaction and/or experiences with online courses to better develop new methods of offering online education on the reservation(s). Further research could include the examination of the teacher and learner-centered approaches and the paradigm shifts between the two. The effects of distance education on tribal communities' integrity, culture and tradition should also be studied.

\section{AUTHORS INFORMATION}

Ahmed Al-Asfour is an Associate Professor at Oglala Lakota College. He teaches business courses. Research interest: Native American education and business matters on the reservations. E-mail: ahmedalasfour@ hotmail.com

Carol Bryant is an Associate Professor of Secondary Education at the University of Wyoming, specializing in social studies education and qualitative research. E-mail: bryantcj@uwyo.edu

\section{REFERENCES}

1. Ambler, M. (1994). Going the distance. Tribal College, 5(4),11-17.

2. Beaudoin, M.F. (2002). Distance education leadership: An essential role for the new century. Journal of Leadership Studies, 8(3), 131-144. Retrieved from ProQuest database.

3. Cakmak, E. K., Karatas, S., \& Ocakm, M. A. (2009).An analysis of factors affecting community college students' expectations on e-learning. The Quarterly Review of Distance Education, 10(4), 351-261.

4. Cummins, J., \& Sayers, D. (1995). Brave new schools: challenging cultural illiteracy through global learning. New York: NY

5. Cross, P, K. (1981). Increasing participation and facilitating learning. San Francisco, CA: Jossey-Bass.

6. Duncan, H. E., \& Young, S. (2009). Online pedagogy and practice: Challenges and strategies. The Researcher, 22(1), 17-32.

7. Dobbs, R.R, Waid, A.C, \& Del Carmen, A. (2009). Students' perceptions of online course: The effect of online course experience. The Quarterly Review of Distance Education, 10 (1). Retrieved from http://web.ebscohost.com proxy/uwlib.edu.

8. Jackson, M, J., \& Helms, M, M. (2008). Student perceptions of hybrid courses: measuring and interpreting quality. Journal of Education for Business, 84(1). Retrieved from

http://web.ebscohost.com.proxy.uwlib.uwyo.edu.

9. Native American College Fund. Retrieved from http://www.collegefund.org/content/tribal_colleges 
10. Noble. D. F. (2003). Digital diploma mills: The automation of higher education. New York: Monthly Review Press.

11. Moore, M, \& Kearsley, G. (2005). Distance education. Belmont, CA: Thomson Wadsworth

12. Merriam, S. B. (2009). Qualitative research: A guide to design and implementation. San Francisco: John Wiley \& Sons, Inc.

13. Thomas, K. Q.( 2001). Local colleges providing online learning programs. Rochester Business Journal, 16 (43), 28.

14. Gavin, J. (1997). AISES [American Indian Science and Engineering Society] Chapter Advisor Handbook (draft edition): Boulder, Co AISES internal publication.

15. Facility and telecommunications needs of tribally controlled community colleges. (1994). Hearing before the Committee on Indian Affairs, United States Senate, $103^{\text {rd }}$ Congress, $1{ }^{\text {st }}$ Session, July 1993. Washington, DC: U.S. Government Printing Office.

16. Petrides, L.A. (2002). Web-based technologies for distributed (or distance) learning: Creating learnercentered educational experiences in higher education classroom. International Journal of Instructional Media, 29 (1), 69-77.

17. Sanchez, J, Stuckey, M.E. \& Morris, R. (1998). Distance Learning in Indian country: Becoming the spider on the web. Journal of American Indian Education, 37 (3). Retrieved from http://vnweb.hwwilsonweb.com.proxy.uwlib.uwyo.edu.

18. Sanchez, J. (1997). Diversifying America's classroom: A perspective from Indian country (compiled proceedings from a conference sponsored by the national communication Association. Annandale, VA: Summer conference on racial and ethnic diversity in the $21^{\text {st }}$ century: A communication perspective.

19. Shortbull, T. Retrieved from http://www.olc.edu/about/

20. Kearsley, G. (2000). Online education: learning and teaching in cyberspace. Belmont, CA: Wadsworth

21. Yang, Y, \& Cornelius, L.F. (2004). Students' perceptions towards the quality of online education: A qualitative approach. Association for Educational Communication and Technology, 27, 861-877. 